\title{
Idiopathic AA amyloidosis manifested by autonomic neuropathy, vestibulocochleopathy, and lattice corneal dystrophy
}

\author{
I Tsunoda, H Awano, H Kayama, T Tsukamoto, S Ueno, T Fujiwara, M Watanabe, \\ T Yamamoto
}

\begin{abstract}
A 69-year-old Japanese woman with nonfamilial amyloidosis had polyneuropathy and profound autonomic neuropathy, and $\boldsymbol{\kappa}$ chain monoclonal gammopathy. Immunohistopathological examination showed protein $A A$ and protein $A P$ in the amyloid deposits. She showed involvement of the vestibulocochlear nerve and lattice dystrophy of the cornea. Vestibulocochleopathy and corneal lattice dystrophy have been reported in familial amyloid polyneuropathy type IV, Finnish type, but never in non-familial amyloidosis.
\end{abstract}

$(\mathcal{F}$ Neurol Neurosurg Psychiatry 1994;57:635-637)

Idiopathic amyloidosis was found in an elderly woman with an unusual constellation of clinical manifestations which consisted of polyneuropathy with profound autonomic failure, lattice dystrophy of the cornea, and vestibulocochleopathy. Amyloid A (AA) type amyloid, common to the secondary systemic form, was identified. The involvement of the vestibulocochlear nerve and corneal lattice dystrophy have not been reported previously in non-familial amyloidosis, but are known in the rare Finnish type. ${ }^{12}$

College, Fukushima, Japan

Department of

Neurology

I Tsunoda

H Kayama

T Tsukamoto

T Yamamoto

H Awano

Department of

Ophthalmology

T Fujiwara

Department of

Otorhinolaryngology

M Watanabe

Department of

Neurology, Osaka

University Medical

School, Osaka, Japan

$S$ Ueno

Correspondence to:

Dr Ikuo Tsunoda,

Department of Neurology,

Fukushima Medical

College, 1 Hikarigaoka

Fukushima 960-12, Japan.

Received 2 June 1992

and in revised form

15 March 1993.

Accepted 23 April 1993 \begin{abstract}
became bedridden. Careful enquiry revealed no family history through five generations.

Case report

A 69-year-old, previously healthy, Japar inability to feed herself as a result of vomiting, orthostatic hypotension, and urinary and rectal dysfunctions. Her history dated back to her forties, when she experienced dizzy spells of several minutes' duration. At the age of 55 years, she had darkening of the vision. Five years later, she egan noticing numbness and paraesthesia in the distal part of the lower extremities, which gradually came up to the waist level. At the age of 68 years, her hearing started to deteriorate gradually; over the next few months she slowly developed weakness of the extremities. She was no longer ambulant because of orthostatic hypotension, and ultimately she
\end{abstract}

Physical examination revealed an anaemic, emaciated woman whose height was $152 \mathrm{~cm}$ and weight $37 \mathrm{~kg}$. The blood pressure (BP) was $122 / 67 \mathrm{mmHg}$ (heart rate $96 / \mathrm{min}$ ) in the supine position; in the sitting position, the BP fell to $52 / 37 \mathrm{mmHg}$ (heart rate $100 / \mathrm{min}$ ).

Neurological examination disclosed bilateral hyposmia and decreased visual acuity (corrected visual acuity: in the right eye$20 / 100$; in the left eye-10/100). There was bilateral lattice corneal dystrophy and senile cataract (fig 1). The pupils were equal and regular, and reacted weakly to light, although better to convergence. Instillation of $1 \cdot 25 \%$ adrenaline into the conjunctival sac caused full pupillary dilatation, suggesting the presence of sympathetic denervation supersensitivity; corneal sensation was decreased. There was bilateral severe sensory deafness, and she had bilateral canal paresis. There was diffuse atrophy and weakness of distal limb muscles. The deep tendon reflexes were diminished in the upper and abolished in the lower extremities. Superficial sensations were markedly diminished in the distal parts of all four extremities, and deep sensations were also moderately diminished in the lower extremities.

\section{LABORATORY FINDINGS}

Liver and renal function tests were unremarkable. Serum $\beta_{2}$-microglobulin was $4.5 \mu \mathrm{g} / \mathrm{ml}$. Serum IgG, IgA, and IgM levels were within normal limits. Serum protein electrophoresis disclosed a monoclonal peak within the $\gamma$ globulin fraction which was later shown to be a monoclonal $\kappa$ chain immunoelectrophoretically. Serum amyloid A protein was $275 \%$

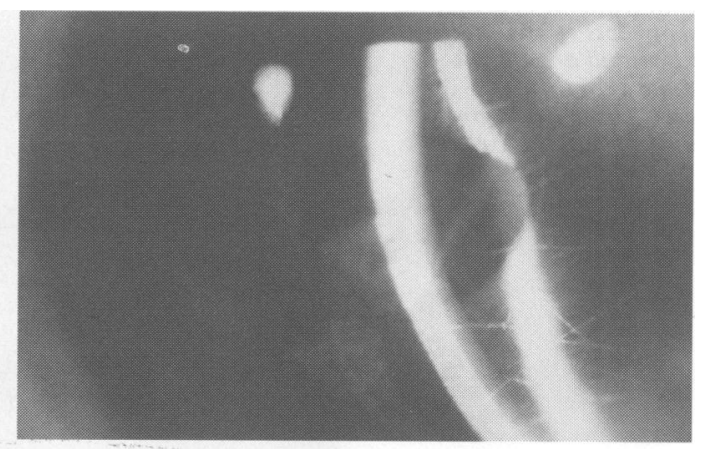

Figure 1 Slitlamp examination demonstrated the typical latticework of branching filaments and a fine central anterior stromal haze. 
(normal, 100\%); CSF was acellular: glucose $3.3 \mathrm{mmol} / 1$, protein $0.54 \mathrm{~g} / \mathrm{l}, \mathrm{IgG} 0.098 \mathrm{~g} / \mathrm{l}$, and albumin $0.416 \mathrm{~g} / 1$.

\section{AUTONOMIC FUNCTIONS}

Basal plasma levels of noradrenaline, dopamine- $\beta$-hydroxylase, and vasopressin failed to rise with a postural change from lying to sitting. Continuous BP monitoring during the Valsalva manoeuvre revealed an impaired phase IV response- the BP recovery was rather slow with no overshoot phenomenon. Cold pressor test was negative, and no lacrimation was demonstrated on the Schirmer test.

\section{ELECTROPHYSIOLOGICAL STUDIES}

Motor and sensory nerve conduction velocities were slightly delayed in all four limbs. Motor action potential (MAP) and sensory action potential (SAP) amplitudes were decreased: peroneal nerve MAP was unobtainable at the right side; ulnar nerve MAP, $2.8 \mathrm{mV}$; median nerve SAP, $17.7 \mu \mathrm{V}$; sural nerve SAP was unobtainable at the right side. The EMG examination disclosed chronic denervation in all four extremities. Brainstem auditory evoked potentials were not evoked even with stimuli of the maximal tone intensity.

The sternal bone marrow aspirate revealed a slight increase in normal appearing plasma cells $(6 \cdot 0 \%)$ and only a few multinucleated plasmacytes.

\section{HISTOLOGICAL FEATURES}

The sural nerve biopsy showed many large and thin myelinated fibres that had undergone wallerian degeneration; segmental demyelination was also found in a few places. Resin embedded, toluidine blue stained sections showed a severe loss of myelinated fibres; islands of amorphous deposits were shown subperineurially and also around the perineurial small blood vessels (fig 2). The deposits, on Congo red staining, gave rise to bright green birefringence using a polarising microscope. Endoscopic biopsies of the stomach and the duodenum also showed amyloid deposits in the submucosal muscular layer. Pre-treatment of the tissue with potassium

Figure 2 A resin embedded section stained with toluidine blue showing severe loss of myelinated fibres and amorphous deposits in the perineurium. (Original magnification $\times 100$ ).

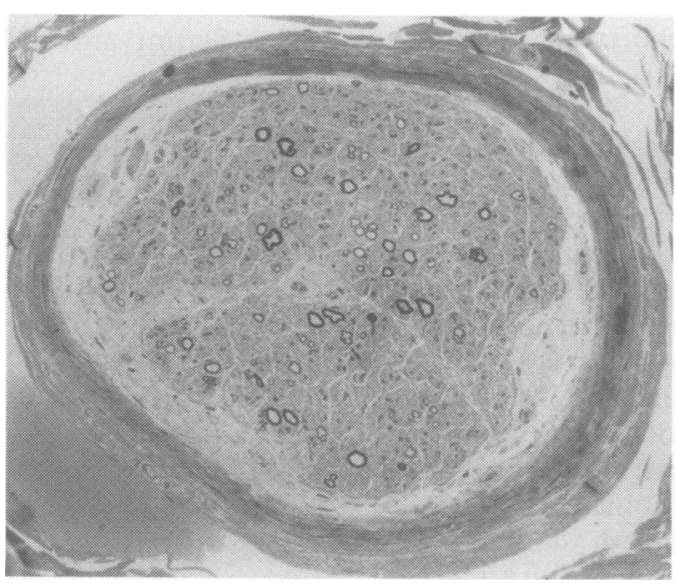

permanganate before Congo red staining totally abolished congophilia, indicating that the amyloid deposits were of protein AA type. Immunoperoxidase histochemical reactions were positive for the amyloid deposits with antibodies to both serum amyloid $A$ and $P$ components, thus indicating that these deposits were indeed of the AA type. A monoclonal antibody against Gelsolin (Sigma, St Louis, Mo., United States) ${ }^{3}$ did not label the deposits immunohistochemically.

\section{GENETIC ANALYSIS}

The mutant gene encoding variant Gelsolin (Asp187) reported in Finnish type ${ }^{45}$ was not detected by a restriction fragment length polymorphism analysis method.

\section{Discussion}

An individual biochemical form of amyloidosis possesses its characteristic clinical features Peripheral neuropathy with autonomic failure is a frequent and often profound manifestation in $\mathrm{AL}$ type primary amyloidosis and familial amyloidosis type I and III; secondary amyloidosis however, only rarely involves the autonomic nervous system. ${ }^{6}$ This case of nonhereditary idiopathic amyloidosis was unusual, as profound involvement of the autonomic nervous system was associated with corneal lattice dystrophy and bilateral vestibulocochleopathy. The initial impression of the authors that this case was of AL type was not substantiated biochemically because of loss of affinity of the amyloid for Congo red after treatment with potassium permanganate-a histochemical property which has proved reliable in distinguishing $\mathrm{AA}$ from $\mathrm{AL}$ type. $^{7}$

Monoclonal gammopathy of $\kappa$ light chain often found in $\mathrm{AL}$ amyloidosis was also identified in the present case, although this is not an ordinary accompaniment to AA amyloidosis; its significance in this case is difficult to explain. The presence of monoclonal gammopathy may be merely coincidental. As underlying disorders could not be found in spite of an exhaustive work-up, this case should preferably be referred to as idiopathic AA amyloidosis, as proposed by Pras et $a l^{8}$, to avoid confusion with the classic primary type.

Involvement of the acoustic nerve is quite unusual in non-hereditary amyloidosis, ${ }^{9}$ although it has rarely been reported in Finnish type ${ }^{12}$ and familial amyloidosis of other forms. ${ }^{10-13}$ Corneal lattice dystrophy has never been reported in non-familial amyloidosis but is virtually pathognomonic of Finnish type. However, the severe involvement of bilateral vestibular and cochlear nerves and the profound autonomic neuropathy shown in this case have not been known in the Finnish type. The amyloid deposits did not react with anti-Gelsolin antibody and the mutant Gelsolin gene was not found in this patient, although the amyloid protein in the Finnish type has been shown to be related to Gelsolin. ${ }^{451415}$ 
The unique clinical features of the idiopathic AA type amyloidosis presented here would indicate that the tissue affinity of the amyloid is different from that of ordinary AA type and so are its biochemical properties. Study of similar cases, together with biochemical analysis of the amyloid, should clarify where this particular case stands in the broad spectrum of amyloidosis.

1 Meretoja J, Teppo L. Histopathological findings of familial amyloidosis with cranial neuropathy as principal ial amyloidosis with cranial neuropathy as principal
manifestation. Acta Pathol Microbiol Scand[A] 1971;79: manifestatic

2 Meretoja J. Familial systemic paramyloidosis with lattice dystrophy of the cornea, progressive cranial neuropathy, skin changes and various internal symptoms. Ann Clin Res 1969;1:314-24.

3 Loeffler KU, Edward DP, Tso MOM. An immunohistochemical study of gelsolin immunoreactivity in cornea amyloidosis. Am $\mathcal{F}$ Ophthalmol 1992;113:546-54.

4 Levy E, Haltia M, Fernandez-Madrid I, et al. Mutation in gelsolin gene in Finnish hereditary amyloidosis. 7 Exp Med 1990;172:1865-7.

5 Maury CPJ, Kere J, Tolvanen $R$ de la Chapelle $A$ Finnish hereditary amyloidosis is caused by a single nucleotide substitution in the gelsolin gene. FEBS Lett 1990;276:75-7.

6 Nordborg C, Kristensson K, Olsson Y, Sourander P. Involvement of the autonomous nervous system in pri-
mary and secondary amyloidosis. Acta Neurol Scand mary and secon.

7 Wright JR, Calkins E, Humphrey RL. Potassium permanganate reaction in amyloidosis. A histologic method to assist in differentiating forms of this disease. Lab Invest 1977;36:274-81.

8 Pras M, Zaretzky J, Frangione B, Franklin EC. AA protein in a case of "primary" or "idiopathic" amyloidosis. Am $\mathcal{F}$ Med 1980;68:291-4.

9 Chambers RA, Medd WE, Spencer H. Primary amyloidosis. $Q \mathcal{F}$ Med 1958;NS27:207-26.

10 Muckle TJ, Wells M. Urticaria, deafness, and amyloidosis: A new heredo-familial syndrome. $Q \mathcal{F} \mathrm{Med} 1962$; NS31:235-48.

11 Van Allen MW, Frohlich JA, Davis JR. Inherited predisposition to generalized amyloidosis. Neurology 1969;19: 10-25.

12 Okayama M, Goto I, Tanaka T, Omae T. Familial primary amyloidosis with vitreous opacities and gastrointestinal symptoms. Report of a case. Rinsho Shinkeigaku 1974;14:293-9.

13 Goren H, Steinberg MC, Farboody GH. Familial oculoleptomeningeal amyloidosis. Brain 1980;103:473-95.

14 Haltia M, Ghiso J, Prelli F, et al. Amyloid in familial amyloidosis, Finnish type, is antigenically and structurally related to gelsolin. Am f Pathol 1990;136:1223-8.

15 Maury CPJ, Alli K, Baumann M. Finnish hereditary amyloidosis. Amino acid sequence homology between the amyloid fibril protein and human plasma gelsoline. FEBS Lett 1990;260:85-7.

\section{Bontius and Tulp on beriberi polyneuropathy}

In chapter 5 of his Observationes medicae, Nicolaus Tulp, stimulated perhaps by his teacher Jacobus Bontius, ${ }^{1}$ describes the beriberi of the East Indies. ${ }^{2}$ Bontius had served as a doctor in Batavia in 1627. His precise observations give the first recognisable picture of polyneuropathy (see also ${ }^{3}$ ):

. . . a kind of paralysis, or rather tremor; for it penetrates the motions and sensations of the hands and feet, indeed sometimes of the whole body . . movement and sensation particularly of the hands and feet are depraved, and they are weak; and in them is felt very often a tickling.

Unfairly judged by the modern genre, Tulp's punctuation is almost as idiosyncratic as his treatment, which the patient survived, perhaps because of his mother's good food.

Joost de Vogelaar, a youth fond of travelling, at that time in a particular part of the orient, was however in the region of Chloromandel, where the Sun sometimes burned so hotly that the natives sought to escape it, . . . this youth to shun such consuming heat, put himself on deck every day under the sky in the air ... they (his servants) bathed him with lots of cold water . . . the youth became sick, he had no power to control by his mind, obstipation as well as fluid in the skin, and the inordinate cold, repercussing excessively in the nerves produced that species of paralysis which is called in India Beriberi, or ovem (sheep).

Tulp inquired into the nature of the disease when his patient returned home:

For it fits in with a partial paralysis, his body was certainly drowsy and languid, and his limbs inert, and inactive, however by no means destitute of motion altogether and albeit sick he was little by little restored to health, gradually taking to food, not only to walk about, but he was permitted to sit in a chair to perform some slight movement, indeed in his dull limbs, now and then a movement was detected, and then that wandering sense of tickling which is accustomed to precede the flowing of animal spirits into the nerves . . . the patient regained his health by the familiar methods of his country and, since the treatment should have been by those very things prescribed specially for this disease from the Chief of the Indies to the Doctors . . . precious oil of the earth which is called Miniac Tennah Indis; and in the Island of Sumatra a trial of this Indian oil is made by us now in chilly disorders of the nerves and deep seated in the muscles.

Additional medication commended included:

. . . cathartics, then Guiac wood, sassafras and China root and externally an ointment partly from petroleum, partly indeed of castor oil, of wax, of the seeds of myristica, of cloves, of peppermint, and of rosewood .... and by the use of all these things, not however constantly, in this manner he was restored to a condition of perfect health.

JMS PEARCE 304 Beverley Road Anlaby, Hull HU10 $7 B G, U K$

1 Bontius J. De medicina Indorum, libr. IV (Leyden: Patuliet, 1745;209). English translation. In: Classic descriptions of
disease, 3rd edn, Ralph H Major, ed. Oxford: Blackwell, 1945;605.

2 Tulp N. Observationes medicae. Ch V. Leyden: Vivie, $1716 ; 286$.

3 Pearce JMS. Robert Graves and multiple neuritis. $\mathcal{F}$ Neurol Neurosurg Psychiatry 1990;53: 113

See also p. 625 